University of Wollongong

Research Online

Faculty of Engineering and Information

Faculty of Engineering and Information

Sciences - Papers: Part A

Sciences

$1-1-2015$

Water extraction from mixed liquor of an aerobic bioreactor by forward osmosis: membrane fouling and biomass characteristics assessment

Wenhai Luo

University of Wollongong, wl344@uowmail.edu.au

Faisal I. Hai

University of Wollongong, faisal@uow.edu.au

William E. Price

University of Wollongong, wprice@uow.edu.au

Long D. Nghiem

University of Wollongong, longn@uow.edu.au

Follow this and additional works at: https://ro.uow.edu.au/eispapers

Part of the Engineering Commons, and the Science and Technology Studies Commons

Research Online is the open access institutional repository for the University of Wollongong. For further information contact the UOW Library: research-pubs@uow.edu.au 


\title{
Water extraction from mixed liquor of an aerobic bioreactor by forward osmosis: membrane fouling and biomass characteristics assessment
}

\author{
Abstract \\ This study investigated membrane fouling and biomass characteristics during water extraction from \\ mixed liquor of an aerobic bioreactor by a submerged forward osmosis (FO) system. As the sludge \\ concentration in the reactor increased from 0 to $20 \mathrm{~g} / \mathrm{L}$, fouling of the FO membrane increased but was \\ much less severe than that of a reference microfiltration membrane. The results also indicate that \\ aeration can be used to effectively control membrane fouling. By increasing the draw solute \\ concentration, as expected, the initial water flux was increased. However, there appears to be a critical \\ water flux above which severe membrane fouling was encountered. A short-term osmotic membrane \\ bioreactor experiment showed build-up of salinity in the bioreactor due to the reverse draw solute \\ transport and inorganic salts rejection by the FO membrane. Salinity build-up in the bioreactor reduced the \\ permeate flux and sludge production, and at the same time, altered the biomass characteristics, leading \\ to more soluble microbial products and less extracellular polymeric substances in the microbial mass. \\ Additionally, the inhibitory effects of the increased salinity on biomass and the high rejection capacity of \\ FO led to the build-up of ammonia and ortho-phosphate in the bioreactor.

\section{Disciplines} \\ Engineering | Science and Technology Studies

\section{Publication Details} \\ Luo, W., Hai, F. I.., Price, W. E. \& Nghiem, L. D. (2015). Water extraction from mixed liquor of an aerobic \\ bioreactor by forward osmosis: membrane fouling and biomass characteristics assessment. Separation \\ and Purification Technology, 145 55-62.
}




\title{
Water extraction from mixed liquor of an aerobic bioreactor
} by forward osmosis: Membrane fouling and biomass

\section{characteristics assessment}

\author{
Revised manuscript submitted to Separation Purification Technology
}

February 2015

Wenhai Luo ${ }^{a}$, Faisal I. Hai ${ }^{\text {a }}$, William E. Price ${ }^{b}$, Long D. Nghiem ${ }^{{ }^{*}}$

${ }^{a}$ Strategic Water Infrastructure Laboratory, School of Civil Mining and Environmental Engineering, University of Wollongong, Wollongong, NSW 2522, Australia

${ }^{b}$ Strategic Water Infrastructure Laboratory, School of Chemistry, University of Wollongong, Wollongong, NSW 2522, Australia

*Corresponding author:longn@ @ow.edu.au; Ph: +61 (2) 42214590. 


\begin{abstract}
This study investigated membrane fouling and biomass characteristics during water extraction from mixed liquor of an aerobic bioreactor by a submerged forward osmosis (FO) system. As the sludge concentration in the reactor increased from 0 to $20 \mathrm{~g} / \mathrm{L}$, fouling of the FO membrane increased but was much less severe than that of the microfiltration membrane. The results also indicate that aeration can be used to effectively control membrane fouling. By increasing the draw solute concentration, as expected, the initial water flux was increased. However, there appears to be a critical water flux above which the higher initial water flux was associated with considerably more severe membrane fouling. A short-term osmotic membrane bioreactor experiment showed the build-up of salinity in the bioreactor due to the reverse draw solute transport and inorganic salts rejection by the FO membrane. Salinity build-up in the bioreactor reduced the permeate flux and sludge production, and at the same time, altered the biomass characteristics, leading to more soluble microbial products and less extracellular polymeric substances in the microbial mass. Additionally, the inhibitory effects of the increased salinity on biomass and the high rejection capacity of FO also led to the build-up of ammonia and ortho-phosphate in the bioreactor.
\end{abstract}

Keywords: Forward osmosis (FO); Osmotic membrane bioreactor (OMBR); Membrane fouling; Aeration; Salinity build-up.

\title{
1. Introduction
}

Membrane bioreactor (MBR), which integrates the physical membrane filtration process with conventional activated sludge (CAS) treatment, is a promising technology for wastewater treatment and reuse. In comparison to CAS, MBRs can offer an improved effluent quality and a lower sludge production $[1,2]$. However, conventional MBRs do not sufficiently remove many trace organic chemicals (TrOCs), particularly those that are hydrophilic and resistant to biodegradation [3]. The molecular dimensions of these TrOCs are much smaller than the pores of either 
microfiltration (MF) or loose ultrafiltration (UF) membranes that are currently used in conventional MBRs [4]. Because TrOCs are readily permeable through these membranes, their residence time in the bioreactor is the same order as the hydraulic retention time (HRT), which is usually very short (i.e. $3-24 \mathrm{~h}$ ) for conventional MBRs [1]. As a result, a post treatment process, such as nanofiltration, reverse osmosis, and/or activated carbon, may be required to further remove TrOCs prior to water reuse applications $[4,5]$.

Efforts to enhance the removal of TrOCs by MBRs have led to the development of a novel process known as osmotic membrane bioreactor (OMBR), which is an integration of forward osmosis (FO) with the CAS treatment [6]. In the OMBR system, water transfers from the mixed liquor, across the semi-permeable FO membrane, to the draw solution using osmotic pressure as the driving force. The high rejection capacity of the FO membrane can effectively retain small and/or biologically recalcitrant TrOCs and thus prolong their residence time in the bioreactor for further biodegradation [7].

The osmotically driven nature allows the FO membrane to have a lower fouling propensity compared to hydraulic pressure driven MF and UF membranes. Thus, the OMBR system can potentially be used as a low fouling alternative to conventional MBRs [6]. However, the fouling behavior of the FO membrane during OMBR treatment is still poorly understood. Lay et al. [8] and Qiu et al. [9] reported a low degree of membrane fouling during OMBR operation. On the other hand, severe fouling of the FO membrane was observed by Zhang et al. [10] and Holloway [11]. Unlike MF/UF membranes that can be hydraulically backwashed, FO membranes can only be chemically cleaned or osmotically backwashed. As a result, it is necessary to further understand the fouling behavior of the FO membrane and develop efficient and cost-effective control strategies of fouling, such as air scouring, for OMBR application, especially under demanding conditions (e.g. high water flux and sludge concentration). 
Aeration is an important operating parameter for submerged MBRs, which provides oxygen for biomass, prevents sludge settlement, and scours the membrane surface. The hydrodynamic shear force induced by aeration can control the deposition of suspended solids on the membrane surface [12]. It is noteworthy that aeration can account for up to $70 \%$ of the overall energy consumption of a submerged MBR system [2]. In addition, excessive aeration is counterproductive as a high hydrodynamic shear force can result in floc breakage and exacerbate pore blocking [13]. Thus, the specific aeration demand of approximately 15 and $30 \mathrm{~m}^{3} / \mathrm{m}^{2} \mathrm{~h}$ is typically used for conventional MBRs using submerged hollow fiber and plate-and-frame membranes, respectively [2]. Despite the potential of OMBR, it is surprising to note the dearth of information regarding the effects of aeration on membrane fouling and biological performance of OMBR in the literature. Recent studies by Zhang et al. [14] and Qiu et al. [15] are the only two exceptions. Zhang et al. [14] observed a thick biofilm on the FO membrane surface and attributed it to the low aeration rate used in their study. It is noteworthy that both Zhang et al. [14] and Qiu et al. [15] did not attempt to investigate influence of aeration and other operating conditions (e.g. draw solute concentration) on membrane fouling.

The high rejection capacity of the FO membrane and the reverse draw solute transport leads to the build-up of salinity in the bioreactor during OMBR operation [8]. Feeding with highly saline wastewater has been reported to adversely affect sludge characteristics and thus worsen membrane fouling in conventional MBRs [16]. Zhang et al. [17] have also showed impacts of sludge characteristics on the flux behavior of OMBR by comparing twenty kinds of activated sludge from different biological treatment processes. However, little is known about the effect of salinity build-up on sludge characteristics and subsequently membrane fouling as well as process performance during OMBR treatment.

This study aimed to investigate the fouling behavior and biomass characteristics during water extraction from activated sludge by an aerated submerged FO membrane. 
Fouling behaviors of aerated submerged MF and FO membranes as a function of sludge concentration were compared to provide a systematic understanding of the role of aeration in fouling control. We also examined the performance of the aerated submerged FO membrane under different operating conditions to optimize the OMBR system. Additionally, a short-term OMBR experiment was performed to evaluate the build-up of salinity in the bioreactor and its associated effects on biomass characteristics, membrane fouling, and process treatment performance.

\section{Materials and methods}

\subsection{Activated sludge}

Activated sludge was collected from the Wollongong Wastewater Treatment Plant (Wollongong, Australia). The activated sludge obtained was thickened by centrifugation at $2167 \mathrm{~g}$ for $2 \mathrm{~min}$ (Allegra X-12R, Beckman Coulter, USA). The thickened sludge was stored at $4{ }^{\circ} \mathrm{C}$ and used for all experiments in this study.

\subsection{Membranes}

A cellulose-based FO membrane supplied by Hydration Technology Innovations (Albany, USA) was used. The membrane consisted of a cellulose triacetate active layer reinforced by a polyester mesh for mechanical support [18]. The FO membrane was mounted on a submersible plate-and-frame module made of Acrylic glass with an effective membrane surface area of $300 \mathrm{~cm}^{2}$. Once mounted, the membrane sealed the draw solution flow channel with length, width and height of 20,15 , and $0.4 \mathrm{~cm}$, respectively. The other side of the membrane was directly exposed to the feed solution. This membrane was asymmetric and could be operated in both FO mode (i.e. the membrane active layer in contact with the feed solution) and pressure retarded osmosis (PRO) mode (i.e. the membrane support layer in contact with the feed solution).

A submersible hollow fibre MF membrane module (SADF0790M mini module, Mitsubishi Rayon Engineering, Japan) was also used for a comparison with FO for 
water extraction from the bioreactor mixed liquor. This MF membrane was made of polyvinylidene fluoride with a nominal pore size of $0.4 \mu \mathrm{m}$ and an effective membrane surface area of $740 \mathrm{~cm}^{2}$, respectively.

\subsection{Experimental systems}

The FO and MF modules were integrated interchangeably with a $10 \mathrm{~L}$ rectangular glass reactor to form the submerged FO and MF filtration systems, respectively (Fig. 1). The effective cross-sectional area of the reactor was $224 \mathrm{~cm}^{2}$. An air pump (Heilea, model ACO 012, China) was used to aerate the reactor via a coarse bubble diffuser (Aqua One, Australia) located at the bottom of the tank to prevent sludge settlement and scour the membrane. The aeration rate could be controlled within the range of $0-$ $6 \mathrm{~L} / \mathrm{min}$ by a valve mounted on the rotameter (Cole-Parmer, Vernon Hills, USA).

In addition to the membrane module and the reactor, the FO filtration system was also equipped with a draw solution delivery and control equipment. A gear pump (Micropump, Vancouver, USA) was used to circulate the draw solution $(\mathrm{NaCl})$ from a draw solution reservoir to the membrane module. The draw solution reservoir was placed on a digital balance (Mettler-Toledo, Hightstown, USA) connected to a computer. The balance readings indicated the amount of water extracted per unit time through the membrane, and this was used to calculate the FO membrane flux. The draw solution flow rate was monitored by a rotameter (Cole-Parmer, Vernon Hills, USA). The draw solution concentration was controlled using a conductivity probe (Cole-Parmer, Vernon Hills, USA), a conductivity controller (Cole-Parmer, Vernon Hills, USA), and a Masterflex peristaltic pump (Cole-Parmer, Vernon Hills, USA). Further details of this concentration control unit are available elsewhere [19]. Briefly, as the draw solution conductivity (i.e. concentration) decreases below the lower set point, the conductivity controller triggers the peristaltic pump to dose a concentrated draw solution $(6 \mathrm{M} \mathrm{NaCl})$ into the draw solution reservoir until the upper set point is reached. The concentrated draw solution $(6 \mathrm{M} \mathrm{NaCl})$ reservoir was also placed on the same digital balance as the working draw solution reservoir to avoid experimental 
errors caused by the concentration control system. The control accuracy of this system is $0.1 \mathrm{mS} / \mathrm{cm}$ (corresponding to approximately $0.78 \mathrm{mM} \mathrm{NaCl}$ ).

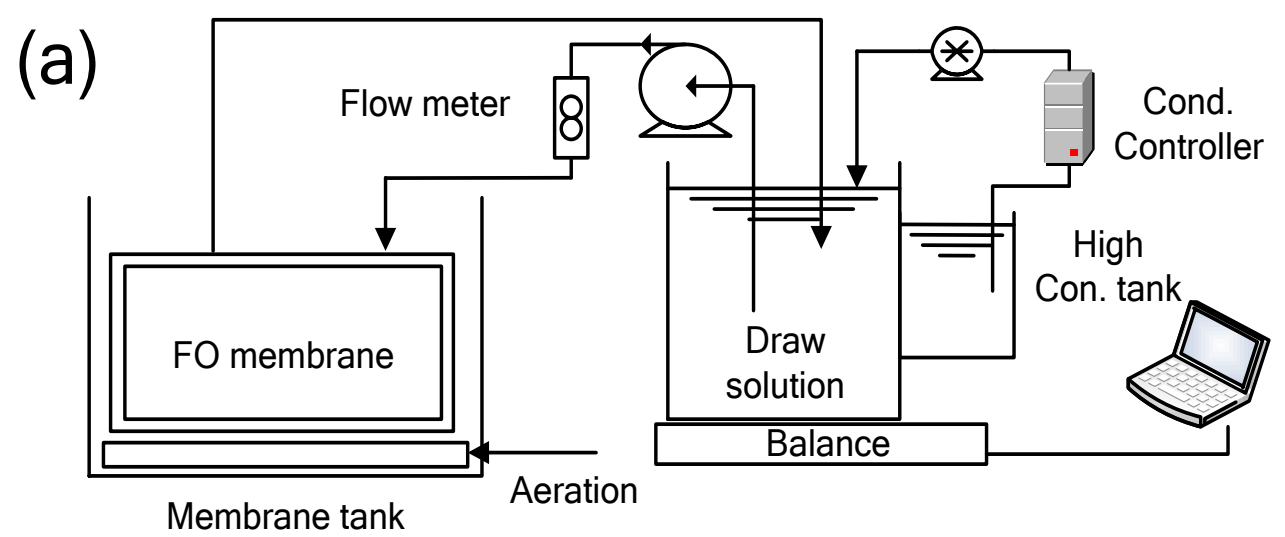

(b)

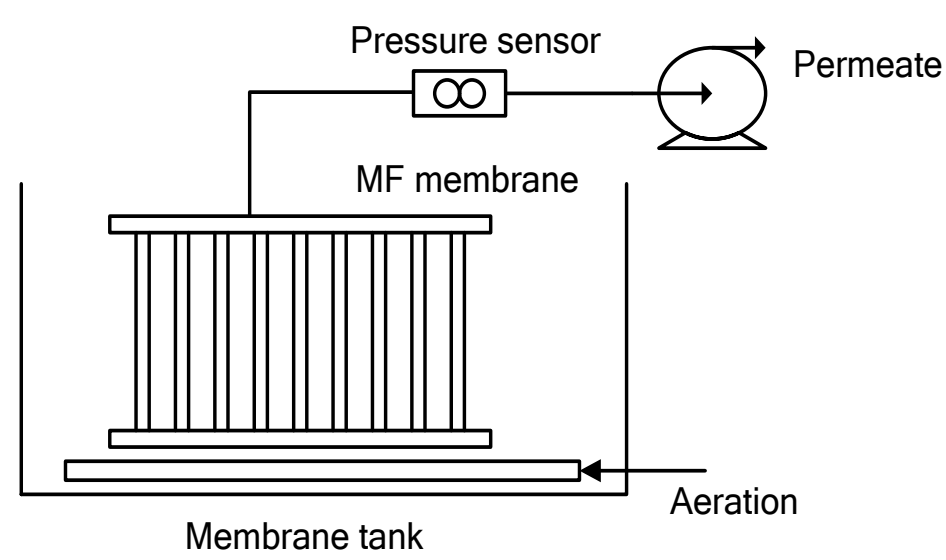

Fig. 1 Schematic diagram of a lab-scale submerged (a) FO and (b) MF filtration system.

In the MF filtration system (Fig. 1b), a computer controlled Masterflex peristaltic pump (Cole-Parmer, Vernon Hills, USA) was used for water extraction. A high resolution $( \pm 0.1 \mathrm{kPa})$ pressure sensor (Extech Equipment, Australia) was used to monitor the transmembrane pressure (TMP).

\subsection{Experimental protocol}

In the FO and MF filtration experiments, the effect of sludge concentration on membrane fouling was investigated under similar conditions. The thickened activated sludge was diluted with synthetic wastewater (Table S1, Supplementary Data) to obtain an initial mixed liquor suspended solids (MLSS) concentration in the range of 
$0-20 \mathrm{~g} / \mathrm{L}$. It is noteworthy that the mixed liquor was concentrated over time due to clean water extraction through membranes.

In the MF filtration experiments, the membrane module was operated in a cycle of 14 min on and 1 min off for membrane relaxation. The membrane module was backwashed with $1 \% \mathrm{NaOCl}$ solution, and then flushed with deionized water at the conclusion of each MLSS concentration experiment. Membrane permeability recovery after flushing was verified by measuring the water flux at a standard condition.

The initial water fluxes of the MF and FO membranes were same at each MLSS concentration. The MF membrane was operated in a constant flux mode and the TMP was measured to calculate the membrane permeability. Given the different driving forces used for FO and MF, the normalized FO water flux and MF permeability at the end of each MLSS concentration experiment were used for comparison.

Unless otherwise stated, all FO experiments were conducted with the standard conditions as follows. The initial MLSS concentration was approximately $8 \mathrm{~g} / \mathrm{L}$. The initial and final mixed liquor volumes were 7 and $4.5 \mathrm{~L}$, respectively (i.e. $35 \%$ water recovery or $2.5 \mathrm{~L}$ of permeate). A new membrane sample was used for each experiment. The membrane bioreactor was continuously aerated with an aeration rate of $2 \mathrm{~L} / \mathrm{min}$, corresponding to a specific aeration demand $\left(\mathrm{SAD}_{\mathrm{m}}\right)$ of $4 \mathrm{~m}^{3} / \mathrm{m}^{2} \mathrm{~h}$, to control membrane fouling and prevent sludge settlement. The $\mathrm{SAD}_{\mathrm{m}}$ was calculated by dividing the volumetric airflow rate by the effective membrane surface area [12]. The $1 \mathrm{M} \mathrm{NaCl}$ solution was used as the draw solution with a cross-flow rate of 1 $\mathrm{L} / \mathrm{min}$, corresponding to a cross-flow velocity of $2.78 \mathrm{~cm} / \mathrm{s}$. The membrane was operated in the FO mode (i.e. the membrane active layer in contact with the feed solution).

The effects of aeration and initial water flux on the FO membrane fouling were also evaluated. For aeration experiments, the $\mathrm{SAD}_{\mathrm{m}}$ was monitored and controlled by a 
rotameter within the range of $0-12 \mathrm{~m}^{3} / \mathrm{m}^{2} \mathrm{~h}$. In addition, the water flux behavior was also examined under three intermittent aeration scenarios (i.e. aeration on/off times of $5 / 5 \mathrm{~min}, 5 / 10 \mathrm{~min}$, and $5 / 15 \mathrm{~min}$ ) with $\mathrm{SAD}_{\mathrm{m}}$ of $4 \mathrm{~m}^{3} / \mathrm{m}^{2} \mathrm{~h}$. The initial MLSS concentration in the aeration experimental series was adjusted to approximately 16 $\mathrm{g} / \mathrm{L}$ to better investigate the air scouring efficiency. Initial water flux was determined using the draw solute $(\mathrm{NaCl})$ concentration within the range of $0.5-2 \mathrm{M}$. The reverse salt $(\mathrm{NaCl})$ flux was calculated by measuring the increase in the mixed liquor conductivity over time.

In the short-term OMBR experiment, synthetic wastewater was continuously fed to the system to maintain a constant reactor volume (Fig. S1, Supplementary Data). The bioreactor was initially seeded with the thickened activated sludge (section 2.1). The initial MLSS concentration was adjusted to approximately $8 \mathrm{~g} / \mathrm{L}$. The $\mathrm{SAD}_{\mathrm{m}}$ and draw solution concentration were maintained at $4 \mathrm{~m}^{3} / \mathrm{m}^{2} \mathrm{~h}$ and $1 \mathrm{M} \mathrm{NaCl}$, respectively. No sludge was discharged over the experimental period of 2 weeks. Given the gradual decrease in the water flux of OMBR, the feeding flow rate was adjusted twice every day to match the permeate flux. Thus, the HRT increased from approximately $21 \mathrm{~h}$ at the beginning to $42 \mathrm{~h}$ at the conclusion of the experiment. All experiments in current study were conducted in a temperature-controlled room $\left(21 \pm 1^{\circ} \mathrm{C}\right)$.

\subsection{Analytical methods}

\subsubsection{Basic water quality measurement}

Total organic carbon (TOC) and total nitrogen (TN) were analyzed using a TOC/TN- $\mathrm{V}_{\mathrm{CSH}}$ analyser (Shimadzu, Japan). Ammonium nitrogen $\left(\mathrm{NH}_{4}{ }^{+}-\mathrm{N}\right)$ and ortho-phosphate $\left(\mathrm{PO}_{4}{ }^{3-}\right)$ were analyzed using a Flow Injection Analysis system (QuichChem 8500, Lachat, USA). In the OMBR system, contaminants transferred into the permeate was diluted by the draw solution. Thus, a dilution factor $(D F)$ was introduced using a mass balance:

$$
D F=\frac{V_{D S}}{V_{F O}}
$$


where, $V_{\mathrm{DS}}$ is the total volume of draw solution when taking samples and $V_{\mathrm{FO}}$ is the FO permeate volume. The contaminant removal by OMBR was determined by:

$$
R=\left(1-\frac{C_{D S}}{C_{I n f}} D F\right) \times 100
$$

where $C_{\text {Inf }}$ and $C_{\mathrm{DS}}$ is the contaminant concentration in the influent and draw solution, respectively.

\subsubsection{Biomass characterization}

Soluble microbial product (SMP) and extracellular polymeric substances (EPS) were extracted according to the thermal method and were normalized as the sum of protein and polysaccharide [20]. Protein was measured by the Folin method using bovine serum albumin as the standard. Polysaccharide was determined based on the phenol-sulphuric acid method using glucose as the standard. Sludge relative hydrophobicity was measured based on a modified MATH-test [21]. Specific oxygen uptake rate (SOUR) of the sludge was determined based on the method described by Choi et al. [22]. MLSS and mixed liquor volatile suspended solids (MLVSS) concentrations were measured in accordance with the Standard Methods for the Examination of Water and Wastewater. Mixed liquor conductivity and $\mathrm{pH}$ were measured using an Orion 4-Star Plus pH/conductivity meter (Thermo Fisher Scientific, USA).

\subsubsection{Membrane morphology analysis}

The surface morphology of the virgin and used membrane in the short-term OMBR experiment was characterized using a scanning electron microscope (SEM) (JEOL JCM-600, Tokyo, Japan). Prior to analysis, the membrane samples were air-dried in a desiccator and then coated with an ultra-thin layer of gold using a gold coating sputter (SPI Module, West Chester, USA).

\section{Results and discussion}

\subsection{Water extraction from the mixed liquor by FO}




\subsubsection{Impact of MLSS concentration on flux}

The impact of MLSS concentration on the water flux of the FO membrane was assessed as an important factor determining their application in conjunction with bioreactors. The fouling behavior of the FO membrane was contrasted with that of a MF membrane, which has been traditionally used to extract water from the mixed liquor of aerobic bioreactors. Given the difference in the driving forces used for FO and MF membranes, the normalized FO water flux and MF permeability at the end of each MLSS concentration experiment were calculated for comparison (section 2.4). In the FO process, the normalized water flux decreased to 0.65 as the initial MLSS concentration increased to $20 \mathrm{~g} / \mathrm{L}$ (Fig. 2). By contrast, in the MF process, the normalized permeability dropped markedly as the initial MLSS concentration increased. At the initial MLSS concentration of $20 \mathrm{~g} / \mathrm{L}$, the normalized permeability of the MF membrane was only 0.03 . The permeability calculated here takes into account the resistance of the membrane as well as the fouling layer. Thus, the rapid decrease in the normalized permeability observed in Fig. 2 indicates fouling conditions associated with the MF process and that the severity of membrane fouling increased proportionally to the MLSS concentration.

While the severe membrane fouling condition at high MLSS concentrations observed with the MF process could possibly be attributed to the lack of strong air scouring, results reported in Fig. 2 highlight the distinct difference in fouling behavior between FO and MF. Wu and Huang [23] have showed that high MLSS concentration could increase the mixed liquor viscosity and thus yield unfavorable fluid rheology in conventional MBRs. Indeed, given the increase in membrane fouling as a function of the solids content, the MLSS concentration limit for almost all full-scale MBR systems is $20 \mathrm{~g} / \mathrm{L}[1]$. 


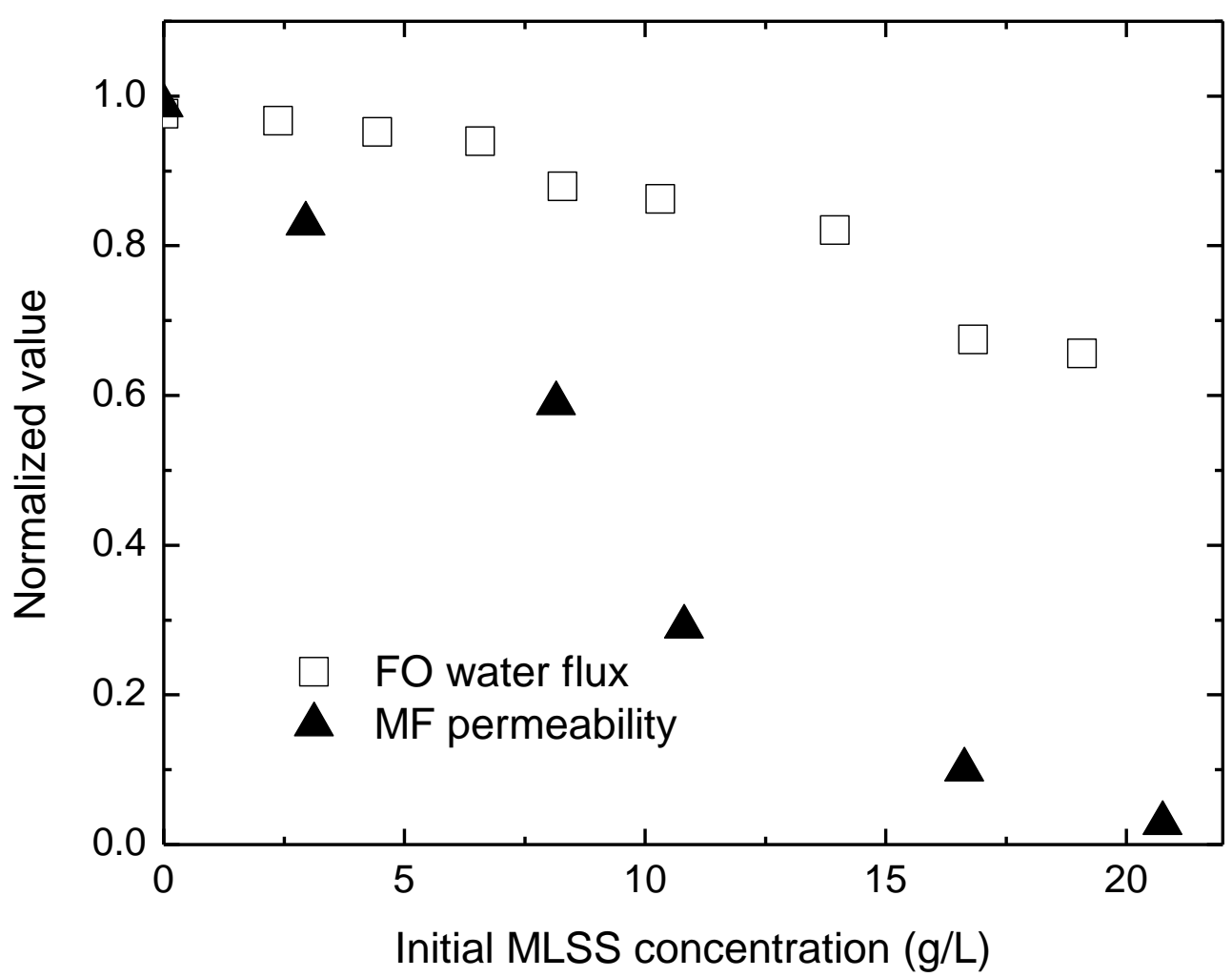

Fig. 2: Normalized FO water flux and MF permeability at the end of each MLSS concentration experiment. The initial water fluxes of the MF and FO membranes were same at each MLSS concentration value. The MF membrane was operated in a constant flux mode and the TMP over time was measured to calculate the membrane permeability. Experimental conditions: FO mode; $\mathrm{SAD}_{\mathrm{m}}=4 \mathrm{~m}^{3} / \mathrm{m}^{2} \mathrm{~h}$; draw solution = $1 \mathrm{M} \mathrm{NaCl}$; cross-flow rate $=1 \mathrm{~L} / \mathrm{min}$ (i.e. cross-flow velocity $=2.78 \mathrm{~cm} / \mathrm{s}$ ); initial water flux $=8.3 \pm 0.3 \mathrm{~L} / \mathrm{m}^{2} \mathrm{~h}$.

The low level of membrane fouling associated with the FO process when the initial MLSS concentration increased to $20 \mathrm{~g} / \mathrm{L}$ is consistent with the literature. Qiu et al. [15] reported the fouling of the FO membrane was negligible in OMBR at the MLSS concentration of $5-12 \mathrm{~g} / \mathrm{L}$. In this study, the same initial flux was used for both the FO and MF membranes. The MF membrane was operated at a constant flux. The normalized flux decline during FO experiment at the highest MLSS concentration was approximately $35 \%$ (Fig. 2). Thus, the difference in permeate flux (which may affect membrane fouling to some extent) was insignificant. The osmotically pressure driven 
transport mechanism allows the foulant layer deposited on the FO membrane surface to be less compacted and adhesive [19], which can be easily removed by air bubble scouring. Additionally, particulates cannot penetrate into the densely active layer of the FO membrane [24]. Therefore, FO is not subject to pore blocking, which can be a major fouling mechanism associated with MF membranes due to their microporous nature.

\subsubsection{Role of aeration}

Our data suggests that aeration plays an important role in fouling control of the submerged FO membrane (Fig. 3). Aeration can induce hydraulic turbulence adjacent to the membrane surface and thus limit the formation of cake layer, which is directly related to the severity of external concentration polarization $[12,25]$. Without aeration, the water flux decreased rapidly from $8.0 \mathrm{~L} / \mathrm{m}^{2} \mathrm{~h}$ at the beginning to approximately 2.0 $\mathrm{L} / \mathrm{m}^{2} \mathrm{~h}$ at the conclusion of the experiment (Fig. 3a). In the absence of any hydraulic disturbance near the membrane, particulate matters and possible dissolved organics in the mixed liquor tended to attach to the membrane surface and form a tenacious cake layer (Fig. S2, Supplementary Data). The cake layer would increase the polarization concentration at the membrane surface, thus resulting in a lower water flux. By contrast, air scouring could mitigate the formation of the sludge cake layer on the membrane surface (Fig. S2, Supplementary Data). Indeed, at a $\mathrm{SAD}_{\mathrm{m}}$ of $4 \mathrm{~m}^{3} / \mathrm{m}^{2} \mathrm{~h}$, water flux only declined from approximately $8.5 \mathrm{~L} / \mathrm{m}^{2} \mathrm{~h}$ at the beginning to $5.7 \mathrm{~L} / \mathrm{m}^{2} \mathrm{~h}$ at the end of the experiment. Stable water flux over the entire experimental period could be observed at $\mathrm{SAD}_{\mathrm{m}}$ of 8 and $12 \mathrm{~m}^{3} / \mathrm{m}^{2} \mathrm{~h}$ (Fig. 3a).

In full-scale MBR plants, the aeration directed at membrane cleaning is applied intermittently as an attempt to reducing energy consumption [1, 25]. Thus, in current study, the efficiency of intermittent aeration in fouling mitigation of the submerged FO membrane was assessed. The water flux behavior at the aeration on/off times of $5 / 5$ min closely resembled that when the membrane was continuously aerated (Fig. 3b). By contrast, a significant decrease in the water flux was observed when the 
aeration off time was prolonged to 10 and 15 min. Once again, the flux decline can be attributed to the attachment of the sludge cake layer on the membrane surface during aeration off period. Thus, results reported in Fig. $3 \mathrm{~b}$ indicate that intermittent aeration with short on/off cycles can be a potential strategy to control the fouling of the submerged FO membranes and minimize the energy consumption induced by aeration. 

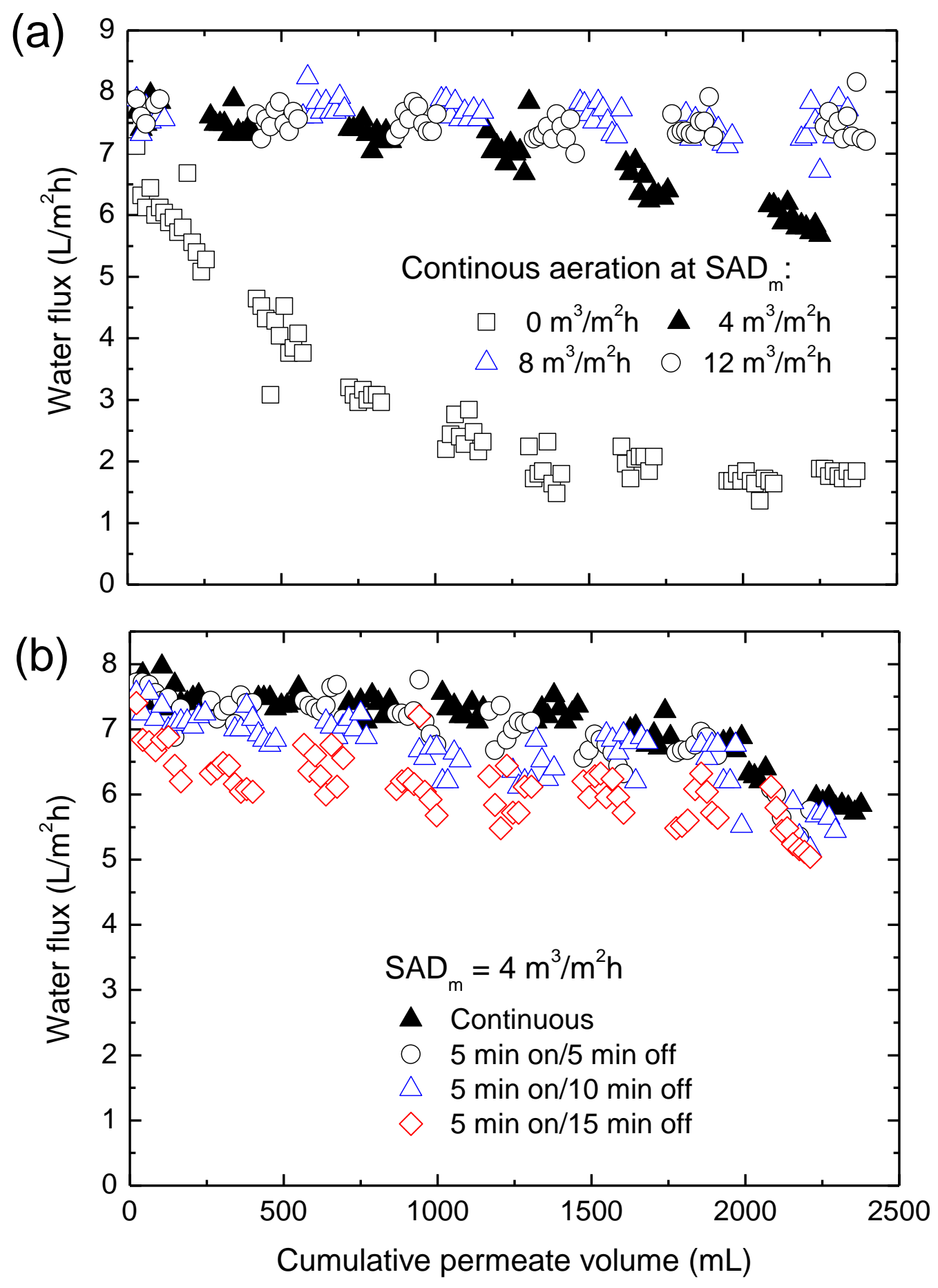

Fig. 3: Effects of (a) specific aeration demand $\left(\mathrm{SAD}_{\mathrm{m}}\right)$ and (b) intermittent aeration on the water flux of FO. Experimental conditions: FO mode; MLSS concentrations = $16.1 \pm 2.7 \mathrm{~g} / \mathrm{L}$; draw solution $=1 \mathrm{M} \mathrm{NaCl}$; cross-flow rate $=1 \mathrm{~L} / \mathrm{min}$ (i.e. cross-flow velocity $=2.78 \mathrm{~cm} / \mathrm{s})$.

\subsubsection{Initial water flux}


As expected, the initial water and revere salt flux increased when the $\mathrm{NaCl}$ draw solution concentration increased (Fig. 4). In the FO process, the osmotic pressure difference across the membrane is the driving force for the transport of both water and draw solute. It is noteworthy that the increase in water flux was not proportional to the increase in the draw solute $(\mathrm{NaCl})$ concentration. Indeed, water flux only doubled when the $\mathrm{NaCl}$ concentration increased four folds from 0.5 to $2 \mathrm{M}$. This disproportionate increase of the water flux in response to the increase of the draw solute concentration may be attributed to the effect of internal concentration polarization (ICP), which is an intrinsic phenomenon in FO. ICP occurs within the membrane porous supporting layer, reducing the net osmotic driven pressure across the interface between the membrane active and supporting layers. ICP is more severe as the draw solute concentration increased [26]. On the other hand, ICP also influenced the reverse salt flux. The reverse salt flux profile closely resembled that of the initial water flux as the draw solute $(\mathrm{NaCl})$ concentration increased (Fig. $4 b)$.

Membrane fouling became more severe as the initial water flux increased (Fig. 4a). At a draw solute $(\mathrm{NaCl})$ concentration of $2 \mathrm{M}$, the water flux decreased gradually from approximately 12 to $8 \mathrm{~L} / \mathrm{m}^{2} \mathrm{~h}$ during the course of the experiment. By contrast, a stable water flux over the entire experimental period could be observed when the initial water flux was either 6 or $8 \mathrm{~L} / \mathrm{m}^{2} \mathrm{~h}$ at the draw solute $(\mathrm{NaCl})$ concentration of 0.5 and $1 \mathrm{M}$, respectively. Similar results have been reported by Xie et al. [19] who examined the effects of initial water flux on organic and colloidal fouling in FO and attributed the substantial flux decline at the high initial water flux to the formation of an adhesive and compacted fouling layer on the membrane surface. Thus, results presented in Fig. 4 suggest that a trade-off between the high water flux versus membrane fouling needs to be considered for OMBR application. 
(a)

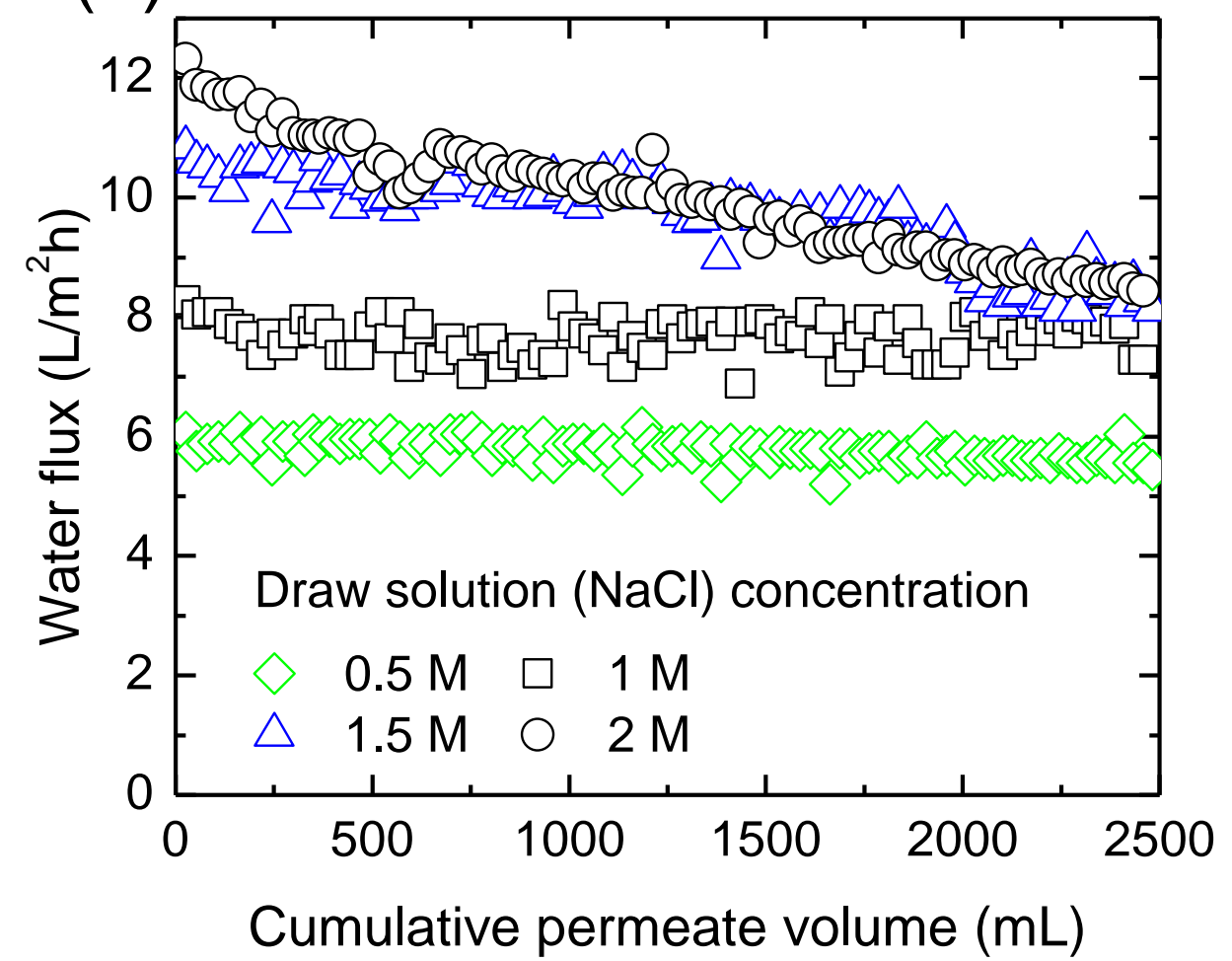

(b)

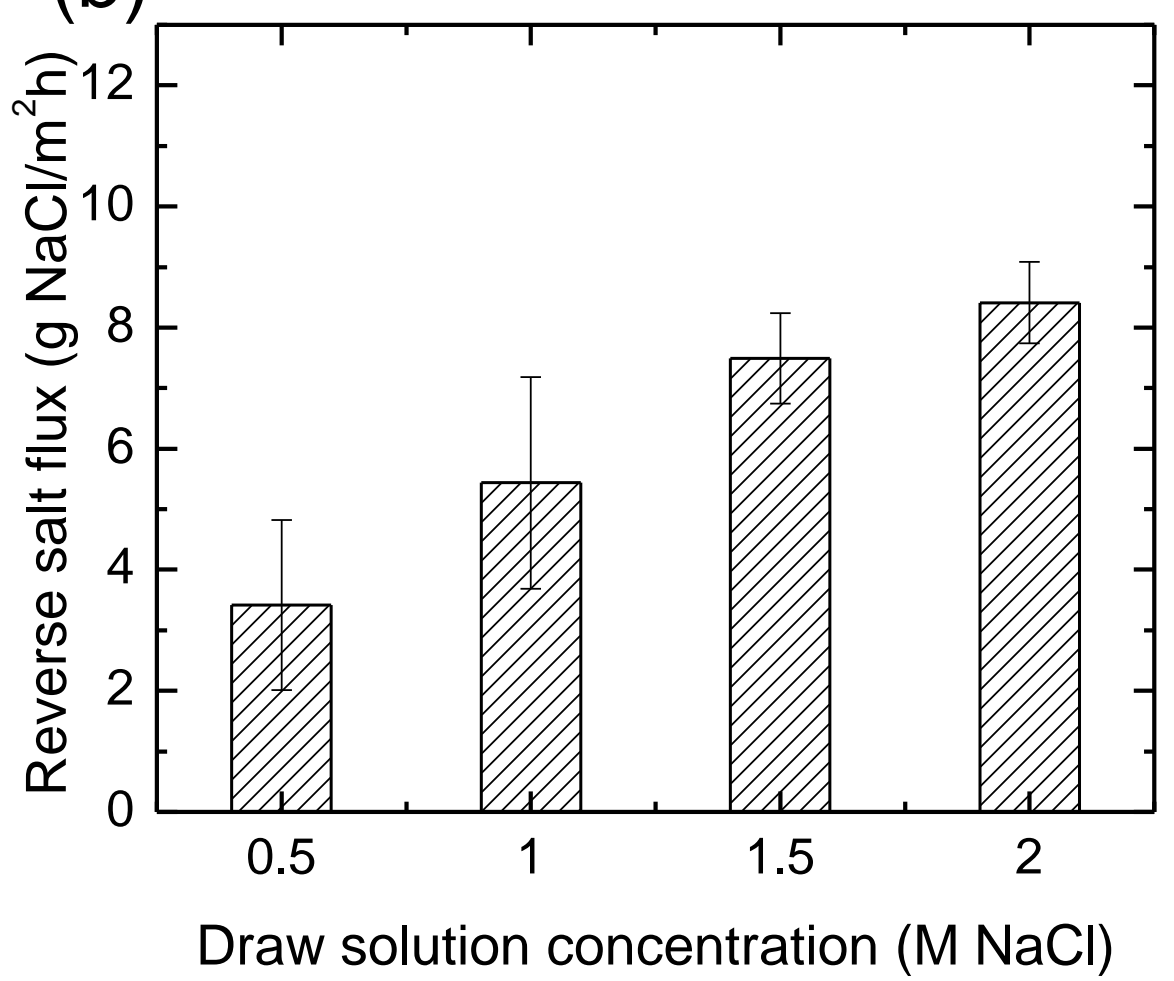

Fig. 4: Effect of draw solute concentration on (a) water flux and (b) reverse salt flux. Experimental conditions: FO mode; MLSS concentrations $=8.2 \pm 1.9 \mathrm{~g} / \mathrm{L} ; \mathrm{SAD}_{\mathrm{m}}=4 \mathrm{~m}^{3} / \mathrm{m}^{2} \mathrm{~h}$; cross-flow rate $=1 \mathrm{~L} / \mathrm{min}$ (i.e. cross-flow velocity $=2.78 \mathrm{~cm} / \mathrm{s}$ ). Error bars in Fig $4 \mathrm{~b}$ represent standard deviation from four measurements (one measurement every $2 \mathrm{~h}$ ). 


\subsection{Performance of OMBR during wastewater treatment}

A continuous OMBR experiment was conducted to preliminarily assess the process performance with regards to the treatment efficiency, membrane fouling, and biomass characteristics. While a small build-up of TOC in the bioreactor was observed, the TOC removal by OMBR was consistently over $98 \%$ during the entire experimental period (Fig. 5a). The TOC build-up in the bioreactor was possibly due to the high rejection of non-biodegradable and/or refractory dissolved organic matters by the FO membrane [27].

In an aerobic bioreactor, TN consumption mainly occurs via assimilation to the microbial mass, and thus it was not a surprise that the TN removal in this study was only $30 \%$. However, under aerobic conditions, $\mathrm{NH}_{4}{ }^{+}-\mathrm{N}$ can be converted to $\mathrm{NO}_{2}{ }^{-}-\mathrm{N}$ and then $\mathrm{NO}_{3}{ }^{-} \mathrm{N}$. Incomplete nitrification is usually manifested by the detection of both $\mathrm{NH}_{4}{ }^{+}-\mathrm{N}$ and $\mathrm{NO}_{\mathrm{x}}{ }^{-} \mathrm{N}$ in the mixed liquor supernatant [1]. The rejection of these nitrogen species by the FO membrane would determine their fate in the bioreactor and the membrane permeate. In this study, the $\mathrm{TN}$ concentration in the bioreactor increased from 40 to $60 \mathrm{mg} / \mathrm{L}$ over the course of the experiment, resulting in a $10 \%$ decrease in TN removal by OMBR (Fig. 5b). The observed decrease in TN removal can be explained by the deteriorating biological performance and incomplete rejection of $\mathrm{NH}_{4}{ }^{+}-\mathrm{N}$ and $\mathrm{NO}_{\mathrm{x}}{ }^{-} \mathrm{-N}$ by the $\mathrm{FO}$ membrane [28-31].

$\mathrm{NH}_{4}{ }^{+}-\mathrm{N}$ build-up in the bioreactor was observed over time (Fig. 5c), which can be ascribed to the inhibitory effect of high salinity of the mixed liquor on nitrification [27]. The increased $\mathrm{NH}_{4}{ }^{+}-\mathrm{N}$ concentration in the bioreactor was accompanied by its transfer into the permeate, reducing the removal of $\mathrm{NH}_{4}{ }^{+}-\mathrm{N}$ from nearly 100 to $75 \%$ over two weeks of operation. $\mathrm{PO}_{4}{ }^{3-}-\mathrm{P}$ build-up in the bioreactor was also observed (Fig. 5d). However, the overall removal of $\mathrm{PO}_{4}{ }^{3-}-\mathrm{P}$ decreased only slightly and was above $96 \%$ throughout the experimental period. This can be attributed to the effective rejection by the FO membrane as ortho-phosphate ions have large hydrated radius and negative charge [28]. 

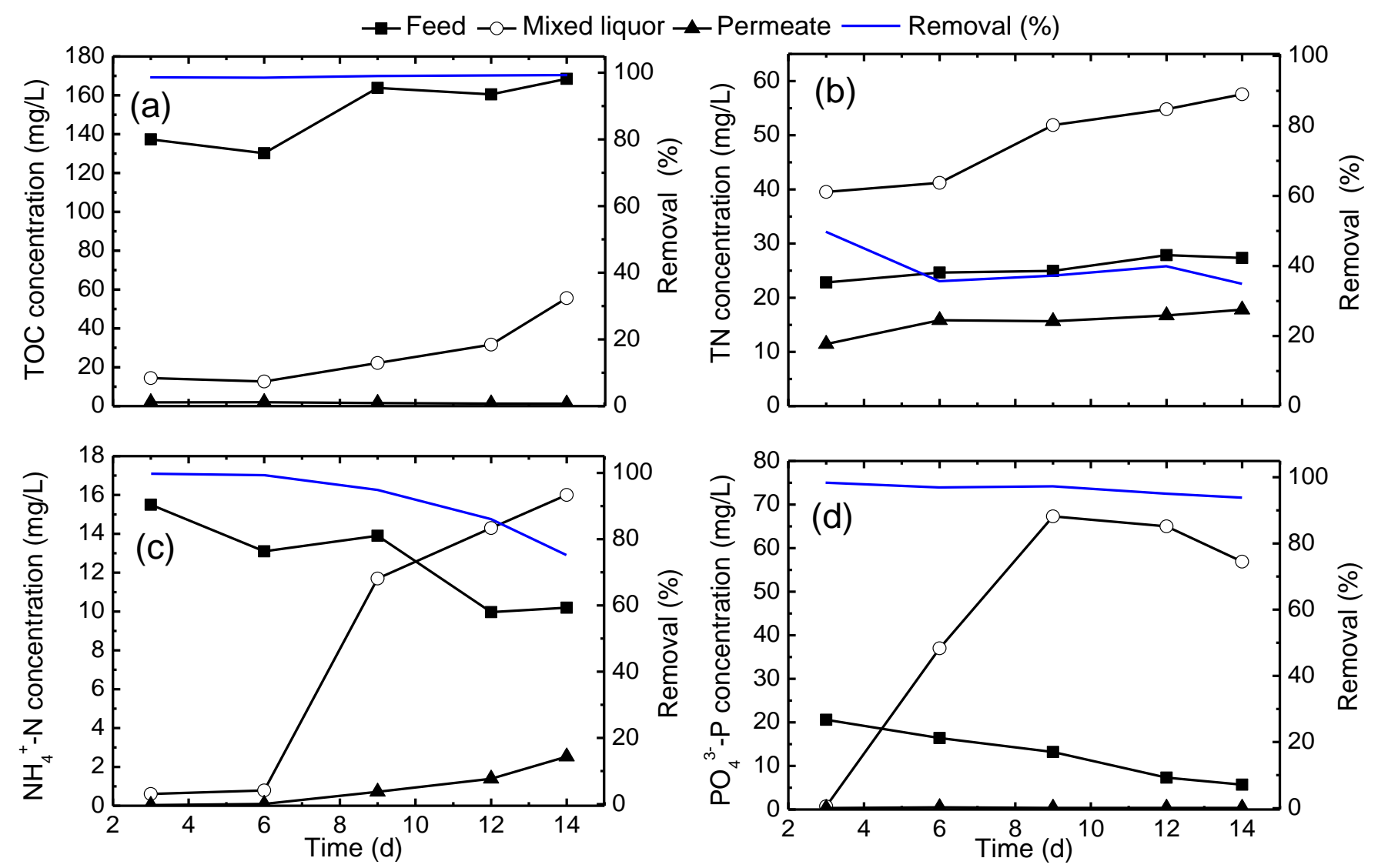

Fig. 5: Organic and nutrient removals by OMBR. Experimental conditions: FO mode, initial MLSS concentration $=8.8 \mathrm{~g} / \mathrm{L} ; \mathrm{SAD}_{\mathrm{m}}=4 \mathrm{~m}^{3} / \mathrm{m}^{2} \mathrm{~h}$; draw solution $=1 \mathrm{M} \mathrm{NaCl}$; cross flow rate $=1 \mathrm{~L} / \mathrm{min}$ (i.e. cross-flow velocity $=2.78 \mathrm{~cm} / \mathrm{s}$ ), initial $\mathrm{HRT}=20.8 \mathrm{~h}$; temperature $=21 \pm 1{ }^{\circ} \mathrm{C}$. 
The mixed liquor salinity increased gradually over time as the OMBR experiment progressed, leading to more reduction in water flux (Fig. 6), compared to the batch experimental results reported in Fig. 4. The build-up of salinity resulted in higher osmotic pressure in the mixed liquor side, leading to a resultant decrease in the water flux and marked changes in biomass characteristics. The impact on biomass characteristics has been discussed in the next section. The mixed liquor conductivity increased rapidly from 0.6 to $19.1 \mathrm{mS} / \mathrm{cm}$ within two weeks of operation. This was the result of inorganic salt rejection from the feed by the FO membrane and the reverse diffusion of $\mathrm{NaCl}$ from the draw solution to the bioreactor.

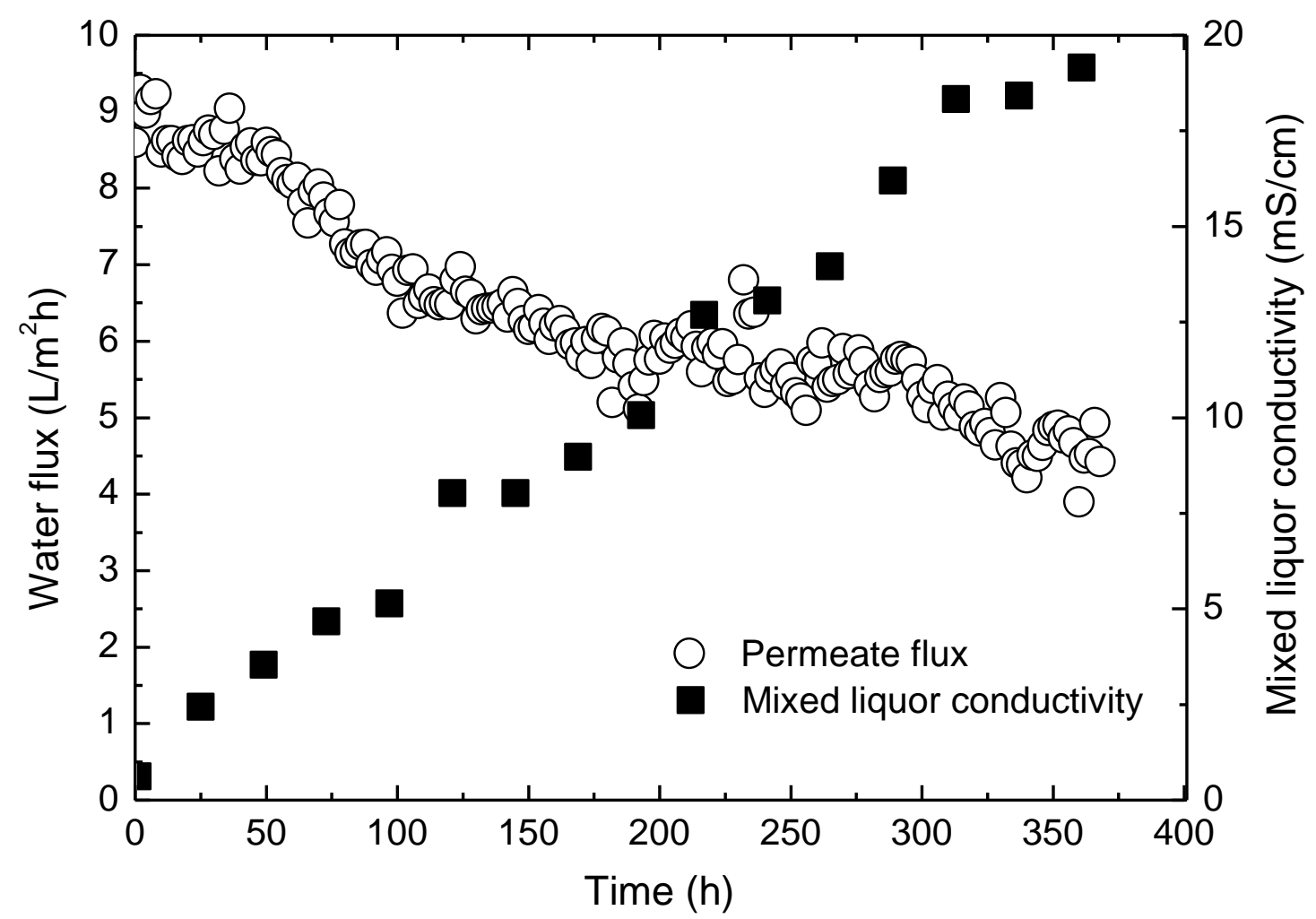

Fig. 6: Variation of water flux and mixed liquor conductivity.

Aeration was effective at preventing cake layer formation on the membrane surface as reported in section 3.1.2. By contrast, a distinctive cake layer was visible by naked eyes in the absence of aeration (Fig. S2, Supplementary Data). Nevertheless, at the conclusion of the short-term OMBR experiment, SEM investigation revealed deposition of amorphous materials, possibly macro-molecules and suspended 
particulate matters on the membrane surface even with aeration (Fig. S3, Supplementary Data). Salinity build-up could enhance the desalting effect, thus increasing the adhesiveness of the suspended materials in the mixed liquor [32].

Notable changes in the biomass characteristics due to salinity build-up were observed after two weeks of continuous OMBR operation (Table 1). The MLVSS/MLSS ratio reduced from 0.68 to 0.60 , indicating the decrease of active biomass in the mixed liquor. The decrease in the MLVSS/MLSS ratio has also been observed by Alturki et al. [7]. Interestingly, the SOUR of the biomass increased as the salinity of the bioreactor increased. This result is similar to a previous study where elevated salinity led to a short-term SOUR increase in a conventional MBR [16], but is in contrast to the observation by Qiu et al [15] and Wang et al [31]. The reason for the increase of SOUR is not clear, but may be due to the enhanced endogenous respiration of the biomass under an elevating salinity condition [33].

Table 1 Biomass characteristics at the beginning and end of the OMBR experiment

\begin{tabular}{ccc}
\hline Characteristics & Beginning & End \\
\hline MLSS (g/L) & 8.8 & 7.8 \\
MLVSS (g/L) & 6.0 & 4.7 \\
MLVSS/MLSS & 0.68 & 0.60 \\
SOUR (mg O $/$ g MLVSS h) & 3.19 & 4.88 \\
SMP (mg/L) & 48.4 & 237 \\
EPS (mg/g MLVSS) & 100.7 & 69.7 \\
Sludge relative hydrophobicity (\%) & 81.2 & 59.8 \\
\hline
\end{tabular}

Salinity build-up in the bioreactor led to an increase in SMP and a decrease in EPS concentration in the mixed liquor. The increase in SMP during OMBR treatment has been reported by Wang et al. [31] who ascribed it to the cell lysis, EPS release, and the accumulation of unmetabolised and/or intermediate products from incomplete degradation of organic matter under the saline condition. The decrease in EPS observed here was probably due to the elevated solubility of the EPS fractions (e.g. protein and carbohydrate) with the mixed liquor salinity [34]. This convention could also increase the SMP concentration in the mixed liquor and reduce the sludge 
hydrophobicity. Compared to EPS, the increased SMP was more likely to result in severe membrane fouling because the membrane was directly exposed to the bulk mixed liquor [35]. It is noteworthy that the biomass characteristics and membrane performance can also be affected by the sludge retention time (SRT) [36]. Thus, the activated sludge taken from conventional treatment processes should be acclimatized under a defined SRT and other operating conditions to further investigate the effects of salinity build-up on OMBR performance during long-term operation.

\section{Conclusion}

The increase in the fouling of the FO membrane was much less severe than that of the MF membrane as the MLSS concentration increased from 0 to $20 \mathrm{~g} / \mathrm{L}$. Fouling of submerged FO membranes can be effectively controlled by aeration. There appears to be a critical water flux at which the FO membrane fouling is negligible. Indeed, the fouling severity of the FO membrane increased as the initial water flux was elevated by increasing the draw solute concentration. In a short-term OMBR experiment, a gradual salinity build-up in the bioreactor could be observed, which resulted in a decrease in the water flux and sludge production, and significantly altered the biomass characteristics. In particular, salinity build-up led to an increase in the SMP concentration and a reduction in EPS in the microbial mass. In addition, the build-up of several other contaminants, including ammonia, total nitrogen and ortho-phosphate, in the bioreactor was also observed.

\section{Acknowledgement}

This research was supported under the Australian Research Council's Discovery Project funding scheme (project DP140103864). The authors would like to thank the Chinese Scholarship Council and the University of Wollongong - Australia for the PhD scholarship support to Wenhai Luo.

\section{References}

[1] F.I. Hai, K. Yamamoto, C.H. Lee, Membrane Biological Reactors: Theory, 
Modeling, Design, Management and Applications to Wastewater Reuse. 2014, IWA Publishing, London.

[2] S. Judd, C. Judd, The MBR book: Principles and Applications of Membrane Bioreactors for Water and Wastewater Treatment. 2011, Oxford: Butterworth Heinemann.

[3] N. Tadkaew, F.I. Hai, J.A. McDonald, S.J. Khan, L.D. Nghiem. Removal of trace organics by MBR treatment: The role of molecular properties, Water Res. 45 (2011) 2439-2451.

[4] L.N. Nguyen, F.I. Hai, J.G. Kang, W.E. Price, L.D. Nghiem. Removal of emerging trace organic contaminants by MBR-based hybrid treatment processes, Int. Biodeterior. Biodegrad. 85 (2013) 474-482.

[5] A.A. Alturki, N. Tadkaew, J.A. McDonald, S.J. Khan, W.E. Price, L.D. Nghiem. Combining $\mathrm{MBR}$ and $\mathrm{NF} / \mathrm{RO}$ membrane filtration for the removal of trace organics in indirect potable water reuse applications, J. Membr. Sci. 365 (2010) 206-215.

[6] A. Achilli, T.Y. Cath, E.A. Marchand, A.E. Childress. The forward osmosis membrane bioreactor: A low fouling alternative to MBR processes, Desalination 239 (2009) 10-21.

[7] A. Alturki, J. McDonald, S.J. Khan, F.I. Hai, W.E. Price, L.D. Nghiem. Performance of a novel osmotic membrane bioreactor (OMBR) system: Flux stability and removal of trace organics, Bioresour. Technol. 113 (2012) 201-206.

[8] W.C.L. Lay, Q. Zhang, J. Zhang, D. McDougald, C. Tang, R. Wang, Y. Liu, A.G. Fane. Study of integration of forward osmosis and biological process: Membrane performance under elevated salt environment, Desalination 283 (2011) 123-130.

[9] G.L. Qiu, Y.P. Ting. Osmotic membrane bioreactor for wastewater treatment and the effect of salt accumulation on system performance and microbial community dynamics, Bioresour. Technol. 150 (2013) 287-297.

[10] J.S. Zhang, W.L.C. Loong, S.R. Chou, C.Y. Tang, R. Wang, A.G. Fane. 
Membrane biofouling and scaling in forward osmosis membrane bioreactor, $\mathrm{J}$. Membr. Sci. 403 (2012) 8-14.

[11] R.W. Holloway, A.S. Wait, A. Fernandes da Silva, J. Herron, M.D. Schutter, K. Lampi, T.Y. Cath. Long-term pilot scale investigation of novel hybrid ultrafiltration-osmotic membrane bioreactors, Desalination (2014) In press, DOI: 10.1016/j.desal.2014.05.040.

[12]A. Drews. Membrane fouling in membrane bioreactors-Characterisation, contradictions, cause and cures, J. Membr. Sci. 363 (2010) 1-28.

[13] F. Meng, F. Yang, B. Shi, H. Zhang. A comprehensive study on membrane fouling in submerged membrane bioreactors operated under different aeration intensities, Sep. Purif. Technol. 59 (2008) 91-100.

[14] Q. Zhang, Y.W. Jie, W.L.C. Loong, J. Zhang, A.G. Fane, S. Kjelleberg, S.A. Rice, D. McDougald. Characterization of biofouling in a lab-scale forward osmosis membrane bioreactor (FOMBR), Water res. 58 (2014) 141-151.

[15] G.L. Qiu, Y.P. Ting. Short-term fouling propensity and flux behavior in an osmotic membrane bioreactor for wastewater treatment, Desalination 332 (2014) 91-99.

[16] W. Luo, F.I. Hai, J. Kang, W.E. Price, W. Guo, H.H. Ngo, K. Yamamoto, L.D. Nghiem. Effects of salinity build-up on biomass characteristics and trace organic chemical removal: Implications on the development of high retention membrane bioreactors, Bioresour. Technol. 177 (2015) 274-281.

[17] H.M. Zhang, Y.J. Ma, T. Jiang, G.Y. Zhang, F.L. Yang. Influence of activated sludge properties on flux behavior in osmosis membrane bioreactor (OMBR), J. Membr. Sci. 390 (2012) 270-276.

[18] J.R. McCutcheon, M. Elimelech. Influence of membrane support layer hydrophobicity on water flux in osmotically driven membrane processes, J. Membr. Sci. 318 (2008) 458-466.

[19] M. Xie, L.D. Nghiem, W.E. Price, M. Elimelech. Impact of organic and colloidal 
fouling on trace organic contaminant rejection by forward osmosis: Role of initial permeate flux, Desalination 336 (2014) 146-152.

[20] X.Q. Zhang, P.L. Bishop, B.K. Kinkle. Comparison of extraction methods for quantifying extracellular polymers in biofilms, Water Sci. Technol. 39 (1999) 211-218.

[21] R. Van den Broeck, P. Krzeminski, J. Van Dierdonck, G. Gins, M. Lousada Ferreira, J.F.M. Van Impe, J.H.J.M. van der Graaf, I.Y. Smets, J.B. van Lier. Activated sludge characteristics affecting sludge filterability in municipal and industrial MBRs: Unraveling correlations using multi-component regression analysis, J. Membr. Sci. 378 (2011) 330-338.

[22] J.H. Choi, S.H. Lee, K. Fukushi, K. Yamamoto. Comparison of sludge characteristics and PCR-DGGE based microbial diversity of nanofiltration and microfiltration membrane bioreactors, Chemosphere 67 (2007) 1543-1550.

[23] J. Wu, X. Huang. Effect of mixed liquor properties on fouling propensity in membrane bioreactors, J. Membr. Sci. 342 (2009) 88-96.

[24] W.J. Yap, J. Zhang, W.C.L. Lay, B. Cao, A.G. Fane, Y. Liu. State of the art of osmotic membrane bioreactors for water reclamation, Bioresour. Technol. 122 (2012) 217-222.

[25] L. Böhm, A. Drews, H. Prieske, P.R. Bérubé, M. Kraume. The importance of fluid dynamics for MBR fouling mitigation, Bioresour. Technol. 122 (2012) $50-61$.

[26] J.R. McCutcheon, M. Elimelech. Influence of concentrative and dilutive internal concentration polarization on flux behavior in forward osmosis, J. Membr. Sci. 284 (2006) 237-247.

[27] J.M. Tan, G. Qiu, Y.P. Ting. Osmotic membrane bioreactor (OMBR) for municipal wastewater treatment and the effects of silver nanoparticles on system performance, J. Cleaner Prod. 88 (2014) 146-151.

[28] R.W. Holloway, A.E. Childress, K.E. Dennett, T.Y. Cath. Forward osmosis for 
concentration of anaerobic digester centrate, Water Res. 41 (2007) 4005-4014.

[29] G.J. Irvine, S. Rajesh, M. Georgiadis, W.A. Phillip. Ion selective permeation through cellulose acetate membranes in forward osmosis, Environ. Sci. Technol. 47 (2013) 13745-13753.

[30] R.W. Holloway, J. Regnery, L.D. Nghiem, T.Y. Cath. Removal of trace organic chemicals and performance of a novel hybrid ultrafiltration-osmotic membrane bioreactor, Environ. Sci. Technol. 48 (2014) 10859-10868.

[31] X. Wang, Y. Chen, B. Yuan, X. Li, Y. Ren. Impacts of sludge retention time on sludge characteristics and membrane fouling in a submerged osmotic membrane bioreactor, Bioresour. Technol. 161 (2014) 340-347.

[32] L.D. Nghiem, A.I. Schäfer, M. Elimelech. Nanofiltration of hormone mimicking trace organic contaminants, Sep. Sci. Technol. 40 (2005) 2633-2649.

[33] M. Ingram. The influence of sodium chloride and temperature on the endogenous respiration of B. cereus, J. Gen. Physiol. 23 (1940) 773-780.

[34] H. Zhang, Z. Gao, L. Zhang, L. Song. Performance enhancement and fouling mitigation by organic flocculant addition in membrane bioreactor at high salt shock, Bioresour. Technol. 164 (2014) 34-40.

[35] F. Meng, B. Shi, F. Yang, H. Zhang. New insights into membrane fouling in submerged membrane bioreactor based on rheology and hydrodynamics concepts, J. Membr. Sci. 302 (2007) 87-94.

[36] K. Kimura, T. Naruse, Y. Watanabe. Changes in characteristics of soluble microbial products in membrane bioreactors associated with different solid retention times: Relation to membrane fouling, Water Res. 43 (2009) 1033-1039. 